\title{
Reflexão acerca dos critérios que podem contribuir para a disseminação da COVID-19 em comunidades quilombolas rurais do estado de Goiás, Brasil*
}

Reflection on criteria that may contribute to the dissemination of COVID-19 in rural quilombolas communities in the state of Goiás, Brazil

Paulo Sérgio Scalize $^{1 * *} \oplus$, Nolan Ribeiro Bezerra² $\odot$, Thaynara Lorrayne de Oliveira' $\odot$, Luis Rodrigo Fernandes Baumann ${ }^{1} \oplus$, Humberto Carlos Ruggeri Júnior ${ }^{1} \oplus$, Raviel Eurico Basso ${ }^{1} \oplus$, Kleber do Espírito Santo Filho' $₫$, Isabela Moura Chagas ${ }^{1} \odot$, Tales Dias Aguiar ${ }^{1} \oplus$, Gabrielle Brito do Vale ${ }^{1} \odot$, Débora de Lima Braga' ${ }^{\circledR}$, Roberta Vieira Nunes Pinheiro ${ }^{1} \odot$

\begin{abstract}
RESUMO
O SARS-CoV-2 é facilmente disseminado por aerossóis e contato direto com pessoas contaminadas. Logo, as condições adversas em áreas rurais podem influenciar a propagação do vírus. Desta forma, estabeleceu-se uma reflexão acerca da disseminação da COVID-19 em função do hábito de lavar as mãos, das condições de saneamento, dos aspectos socioeconômicos e das condições habitacionais em 26 comunidades quilombolas rurais do estado de Goiás. Para isso foram levantadas informações in loco em 533 domicílios e aplicou-se a Analytic Hierarchy Process, utilizando-se critérios selecionados com base na literatura. As comunidades apresentaram uma priorização para a disseminação da COVID-19 variando de 14,9 × 10 ${ }^{-3}$ (pior condição) a 64,3 × 10.3 (melhor condição), na qual a Comunidade José Coleto ocupou a posição mais desfavorável. Buracão mostrou um resultado mais satisfatório, sendo esta menos susceptível à disseminação da COVID-19. A melhoria nas condições de saneamento pode aumentar o hábito da higiene com as mãos, o que reduziria a disseminação da COVID-19 e de outras doenças infecciosas. Assim, a partir dos resultados obtidos, é perceptível a importância do empoderamento quanto aos hábitos de higiene, acesso à informação, saneamento básico e à saúde. Os gestores devem ter uma maior disposição para implantar infraestrutura e melhorar as condições dos critérios apresentados e discutidos neste trabalho.
\end{abstract}

Palavras-chave: COVID-19; lavar as mãos; saneamento rural; quilombola; coronavírus.

\begin{abstract}
SARS-CoV-2 is easily spread by aerosols and direct contact with contaminated people. Therefore, adverse conditions in rural areas can influence the spread of the virus. Thus, a reflection was established about the dissemination of COVID-19 due to the habits of wash hands, sanitation conditions, socioeconomic aspects, and habitability conditions in 26 rural quilombola communities in the state of Goiás. For this, informations were collected in 533 locals households and it was applied the Analytic Hierarchy Process using criteria selected based on the literature. The communities presented a priority for the dissemination of COVID-19 ranging from 14.9 $\times 10^{-3}$ (worst condition) to $64.3 \times 10^{-3}$ (best condition), and the Community José Coleto has occupied the most unfavorable position. Community Buracão showed a more satisfactory result, being less susceptible to the spread of COVID-19. Improving sanitation conditions can increase hand hygiene habits, which would reduce the spread of COVID-19 and other infectious diseases. Thus, from the results obtained, it is noticeable the importance of empowerment regarding hygiene habits, access to information, basic sanitation and health. The managers should give greater attention to implement infrastructures and improve the conditions of the criteria presented and discussed in this paper.
\end{abstract}

Keywords: COVID-19; wash hands; rural sanitation; quilombola; coronavírus.

*Artigo publicado como Edição especial sobre COVID-19, na Revista Engenharia Ambiental e Sanitária: https://www.abes-dn.org.br/wp-content/uploads/2021/O1/Scalize_et_ al_2O21_ESA_versao_publicada-ESA-COVID-7_compressed.pdf

Universidade Federal de Goiás - Goiânia (GÖ), Brasil.

${ }^{2}$ Instituto Federal de Educação, Ciência e Tecnologia de Goiás - Goiânia (GO), Brasil.

**Autor correspondente: pscalize.ufg@gmail.com

Conflitos de interesse: os autores declaram não haver conflitos de interesse.

Financiamento: Fundação Nacional da Saúde (FUNASA) - TED 05.

Recebido: 08/01/2O21 - Aceito: 20/01/2021 - Reg. ABES: 20210006 


\section{INTRODUÇÃO}

A COVID-19 surgiu em dezembro de 2019, inicialmente na China e, em seguida, se espalhou para outros países (SKOLMOWKA, GLABSKA \& GUZEK, 2020). Em fevereiro de 2020, a doença chegou ao Brasil, onde a disseminação se deu a partir de viagens internacionais, principalmente de pessoas de classes média e alta. Logo, diferentes classes trabalhadoras foram contaminadas (SHADMI et al., 2020), atingindo grandes centros urbanos e cidades menores, com potencial de atingir distritos, pequenos povoados e até mesmo comunidades rurais.

Segundo Lana et al. (2020), são sete os coronavírus reconhecidos como patógenos, sendo a COVID-19 causada pelo SARS-CoV-2 (BHOWMICK et al., 2020). O vírus possui alta transmissibilidade (SILVA et al., 2020) e as rotas de contágio se dão por aerossóis e contato direto, ou seja, por meio de pequenas gotículas respiratórias que são eliminadas através de conversas, espirros e tosses, além de utensílios contaminados, abraços e apertos de mão. Logo, uma vez que o vírus entra em contato com a boca e o nariz, ocorre a transmissão (DEHGHANI \& KASSIRI, 2020).

Dentre os estudos, destaca-se a disseminação por meio de águas residuárias (GUERRERO-LATORRE et al., 2020), de resíduos sólidos (ARAÚJO \& SILVA, 2020) e em função da qualidade da água disponível para necessidades básicas, tal como lavar as mãos (GAO et al., 2020; SKOLMOWSKA, GLABSKA \& GUZEK, 2020). O coronavírus também acomete comunidades rurais e seu impacto pode ser variável em função das condições ambientais ali encontradas. Como exemplo, tem-se o vírus H1N1, cuja causa predominante de disseminação foi provavelmente o déficit de saneamento (SUNDARAM et al., 2015). Entretanto, a resposta do vírus se dá pelo perfil imunológico de cada indivíduo e, apesar da crescente relação da falta de saneamento com a COVID-19, o estudo de Kumar e Chander (2020) concluiu que populações que vivem em ambientes inadequados, isto é, em regiões que não apresentam sistemas de esgotamento sanitário adequados e água potável, são mais resistentes à COVID-19, uma vez que são diariamente expostas a uma alta carga microbiana.

Todavia, as medidas impostas por diferentes países não poderiam alcançar todos igualitariamente, uma vez que existem populações vivendo em situações mais vulneráveis (LUO et al., 2020). Deste modo, as comunidades rurais enfrentam desafios para o cumprimento das recomendações contra a COVID-19, uma vez que é comum a falta de instalações e infraestruturas adequadas para promover a saúde dos moradores (DUTTA \& FISCHER, 2021).

Uma forma de avaliar os critérios que podem contribuir para a disseminação da COVID-19 nas comunidades rurais quilombolas é o uso do método Analytic Hierarchy Process (AHP). Esse método se baseia na comparação de critérios par-a-par e permite considerar aspectos qualitativos e quantitativos, auxiliando o tomador de decisão (SAATY, 1987).

Nesse contexto, este trabalho tem como objetivo construir uma reflexão acerca das possibilidades de disseminação da COVID-19 em diferentes comunidades quilombolas do estado de Goiás, em função dos hábitos de lavar as mãos, das condições de saneamento, dos aspectos socioeconômicos e das condições habitacionais, hierarquizando com a aplicação do AHP.

\section{METODOLOGIA}

Dentre as comunidades quilombolas no estado de Goiás, 58 são certificadas pela Fundação Cultural Palmares. Essas comunidades estão inseridas em áreas rurais ou urbanas com características distintas quanto à distância entre seus domicílios e ao acesso aos serviços de saúde. Assim, selecionaram-se 26 comunidades quilombolas rurais do estado de Goiás certificadas pela Fundação Palmares até dezembro de 2017 (Figura 1).

\section{Coleta de dados}

As comunidades foram visitadas e levantaram-se dados sobre os critérios avaliados, conforme plano amostral, por meio de aplicação de um formulário junto ao responsável de cada família. Essa pesquisa foi realizada no âmbito do Projeto Saneamento e Saúde Ambiental em Comunidades Rurais e Tradicionais de Goiás, tendo sido aprovada pelo Comitê de Ética em Pesquisa da Universidade Federal de Goiás, sob o protocolo nº 2.886.174/2018.

\section{Plano amostral}

A quantidade de domicílios visitados foi dimensionada de forma que as estimativas intervalares de proporções fossem obtidas com nível de confiança de $95 \%$, e o erro máximo das estimativas variasse de acordo com os diferentes níveis de abrangência geográfica. Assim, o menor nível de abrangência com controle de precisão das estimativas considerado foi por comunidade, com margem de erro máxima de $10 \%$ e, para a totalidade de comunidades do mesmo tipo, com erro máximo de $3 \%$. Para o cálculo amostral foi empregada, em cada comunidade, a Equação 1,

$n=\frac{N z_{\gamma}^{2} p(1-p)}{(N-1) e^{2}+z_{\gamma}^{2} p(1-p)}$

Onde "N" é o tamanho da população, " $z$ y" é o score da distribuição normal padrão referente ao nível de confiança " $\gamma$ ", "p" é a proporção populacional que se deseja estimar, e " $e$ " é o erro máximo da estimativa (COCHRAN, 1977). Nos cálculos, considerou-se a máxima variabilidade para a estimativa da proporção $(\mathrm{p}=0,5)$. Assim, foram levantadas informações de 533 domicílios de um total de 1,020 existentes nas 26 comunidades quilombolas rurais de Goiás.

\section{Tratamento dos dados}

Para a realização do estudo, utilizou-se o método AHP, seguindo as etapas preconizadas por Saaty (1987), iniciando-se pela definição do objetivo com a estruturação hierárquica, adotando-se os critérios da Tabela 1. Em seguida, a atribuição dos pesos aos critérios foi feita utilizando uma planilha do software Excel, desenvolvida por Goepel (2013). Inicialmente, cada autor deste trabalho, utilizando a escala de julgamento proposta por Saaty (1977), atribuiu notas de 1-9 (variando de igualmente importante $=1$ a extremamente importante $=9) \mathrm{de}$ forma pareada entre os critérios, resultando em um ranking de priorização do seu julgamento em função do seu entendimento do critério com maior importância. A junção da priorização de todos os autores resultou no ranking geral de priorização com os pesos de cada critério apresentados na Tabela 1. A validação dos pesos atribuídos levou em consideração a Razão de Consistência, resultando em 1,5\%, estando abaixo dos 10\% recomendados por Saaty (1987).

Após a atribuição dos pesos, construiu-se a matriz de comparação paritária, na qual se definiu a Equação 2 para atribuir os pesos às comparações paritárias entre as comunidades para um mesmo critério, de forma que refletissem a escala de julgamento atribuída por Saaty (1987),

$f\left(x_{1}, x_{2}\right)=\left(\frac{8\left(e^{0,5\left(x_{2}-x_{1}\right)}-1\right)}{e^{0,5}-1}+1\right)^{\operatorname{sinal}\left(x_{2}-x_{1}\right)}$ 


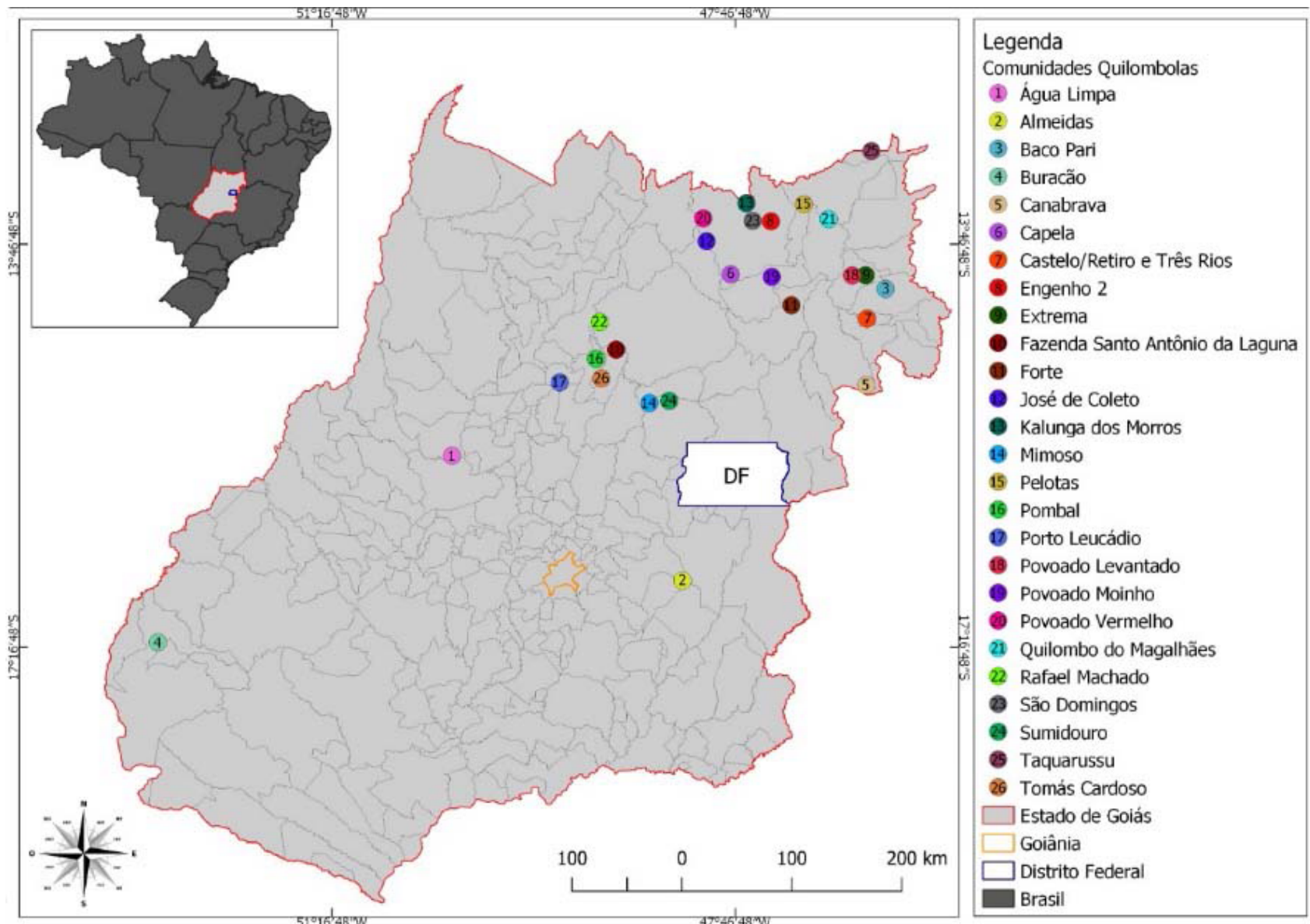

Fonte: elaborada pelos autores.

Figura 1 - Localização das comunidades quilombolas estudadas.

Tabela 1 - Critérios adotados para avaliação da disseminação da COVID-19 em comunidades quilombolas rurais e os pesos atribuídos em ordem de priorização. Critério

\begin{tabular}{|c|c|c|}
\hline 1 & Hábito de lavar as mãos (com água e sabão, antes das refeições e após o uso do banheiro) & 27,5 \\
\hline 2 & Disponibilidade de água (intermitência). & 19,0 \\
\hline 3 & Banheiro com instalação hidrossanitária (chuveiro, lavatório e vaso sanitário) & 13,7 \\
\hline 4 & Acesso à informação (modos de acesso à informação: internet, rádio, televisão, jornal etc.) & 10,2 \\
\hline 5 & Habitabilidade (média de cômodos por habitantes residentes) & 7,6 \\
\hline 6 & Sem lançamento de águas fecais a céu aberto & 5,3 \\
\hline 7 & Trabalho dentro da comunidade (local de trabalho dos moradores da comunidade) & 4,9 \\
\hline 8 & Distância entre a comunidade e o centro urbano (centro urbano mais próximo) & 4,4 \\
\hline 9 & Coleta e transporte de resíduos sólidos & 3,9 \\
\hline 10 & Existência de tratamento da água & 3,5 \\
\hline
\end{tabular}

Fonte: elaborada pelos autores.

Onde $0 \leq x_{1} \leq 1$ e $0 \leq x_{2} \leq 1$ são os valores dos critérios nas comunidades $C_{1}$ e $C_{2}$, respectivamente, sinal $\left(x_{2}-x_{1}\right)$ é igual a 1 , se $\mathrm{x}_{2}-\mathrm{x}_{1} \geq 0$, e - 1 caso contrário. Se o critério não tivesse sido avaliado no intervalo $[0,1]$, teria sido aplicada uma transformação de máximas e mínimas dada por $\mathrm{x}_{\mathrm{T}}=\left(\mathrm{x}-\mathrm{x}_{\min }\right) /\left(\mathrm{x}_{\max }-\mathrm{x}_{\min }\right)$, onde $\mathrm{x}_{\text {máx }}$ e $\mathrm{x}_{\text {min }}$ são a máxima e a mínima do critério entre as 26 comunidades.
Uma vez determinadas as comparações paritárias, utilizou-se o pacote ahpsurvey do software R para aplicação do método AHP, do qual foram obtidas as prioridades (pr) das comunidades em cada critério. Obteve-se a prioridade final (prf) para cada comunidade, considerando-se todos os critérios conjuntamente, pela média das prioridades dos critérios ponderados pelo seu peso 
(Tabela 1). A Razão de Consistência é dada por $\mathrm{CR}=\left(\left(\lambda_{\text {max }}-\mathrm{N}\right) /((\mathrm{N}-1)(\mathrm{RI}))\right.$, na qual RI é o índice de consistência aleatória média (SAATY \& TRAN, 2007). Analisaram-se os resultados hierarquizados e o ranking das comunidades obtidos em ordem de prioridade, para que os gestores pudessem planejar as medidas de controle e evitar a disseminação da COVID-19. Também se calcularam as correlações de Spearman entre as prioridades dos critérios para se entender como as prioridades estão relacionadas (KENDALL \& GIBBONS, 1990).

\section{RESULTADOS}

Nas comunidades analisadas, a média de pessoas por domicílio foi de 3,2, e os resultados obtidos para os critérios avaliados para cada comunidade estão apresentados na Tabela 2, na qual é possível notar que, quanto maior o valor observado, menor será o risco para a disseminação da COVID-19. No Anexo 1, são apresentados os mapas com a distribuição espacial dos domicílios existentes nas comunidades quilombolas rurais do estado de Goiás.

O resultado da aplicação do AHP é apresentado na Tabela 3, possibilitando estabelecer um ranking (prf) entre as comunidades (Figura 2) e observar a pr obtida para cada critério, com CR abaixo de 1,97\% (Tabela 3). Destaca-se que, quanto maior for o valor da prf, menor será a possibilidade de disseminação da COVID-19.

O coeficiente de correlação de Spearman apresentou um amplo espectro de variação entre as priorizações, sendo observadas: a maior correlação positiva entre os critérios "sem lançamento de águas fecais a céu aberto" e "hábito e lavar as mãos" $(0,82)$ e a maior correlação negativa entre os critérios "distância entre a comunidade e centro urbano" e "acesso à informação" (-0,57) (Figura 3).

\section{DISCUSSÃO}

\section{Acesso à informação}

A média de acesso à informação variou de 1,8 a 4,3 modos (Tabela 2), refletindo uma ampla faixa de priorização de $6,84 \times 10^{-3}$ (José de Coleto) a 113,16 × 10-3 (Povoado Moinho) (Tabela 3). Os baixos valores para o critério "acesso médio à informação" indicam maior contribuição para as comunidades com mais modos de acesso à informação.

Dentre os meios de comunicação, ressaltam-se aqueles institucionalizados, tais como revistas, programas de rádio e televisão, assim como os meios de divulgação governamentais veiculados por meio de campanhas informativas em unidades básicas de saúde (FERRARETO \& MORGADO, 2020; MOHAMAD \& AZLAN, 2020). Soma-se a isso a importância que as mídias sociais vêm ganhando ao longo dos anos, sendo uma das principais ferramentas de comunicação (MALECKO, KEATING \& SAFDAR, 2020; HAUER \& SOOD, 2020; SAUD, MASHUD \& IDA, 2020).

Tendo em vista que as comunidades quilombolas historicamente e culturalmente tendem a ser isoladas é de se esperar que os meios de comunicação sejam aqueles mais consolidados. Da mesma forma, meios de comunicação que apresentam maior necessidade de infraestrutura, tais como a internet e os telefones celulares, tendem a ser menos utilizados no meio rural (HANSEN \& CARPENTIER, 2020; HENNING-SMITH, 2020). Esse ponto é corroborado pelo resultado obtido na Figura 3, na qual se observa uma correlação negativa como critério "distância entre comunidade e centro urbano" $(-0,57)$.
Embora a diversidade dos modos de acesso à informação seja fundamental em situação de pandemia, se faz necessário ponderar acerca do processo de curadoria, assim como da qualidade e da confiabilidade das notícias e orientações veiculadas por esses meios (FERRARETO \& MORGADO, 2020). Dentre os efeitos mais perniciosos ligados ao mal uso dos canais virtuais, está a desinformação, que pode levar às práticas que colocam em risco a saúde dos indivíduos, à confusão generalizada e ao pânico social, contribuindo de modo substancial para o agravamento da crise (MALECKI, KEATING \& SAFDAR, 2020; HAUER \& SOOD, 2020; SAUD, MASHUD \& IDA, 2020; RIMAL \& LAPINSKI, 2020).

\section{Disponibilidade e tratamento de água}

A indisponibilidade ou intermitência de água leva as pessoas a buscarem fontes alternativas, podendo permanecer em filas para conseguir tal recurso, o que pode possibilitar a disseminação da COVID-19 (ZVOBGO \& DO, 2020; EKUMAH et al., 2020). Assim, neste estudo, a disponibilidade de água sem intermitência foi o critério que apresentou o segundo maior peso (19,0\%) (Tabela 1), sendo que $44,3 \%$ dos domicílios não sofrem desse problema (Tabela 2). A melhor prioridade $\left(97,30 \times 10^{-3}\right)$ foi observada em seis comunidades, e a pior $\left(8,23 \times 10^{-3}\right)$ em dez comunidades (Tabela 3 ).

Estudos mostram que o RNA SARS-CoV-2 tem sido encontrado em águas de mananciais superficiais, geralmente resultando do lançamento de efluentes (SHUTLER et al., 2020; CARRATURO et al., 2020; Carducci et al., 2020). O SARS-CoV-2 ainda não foi encontrado em água utilizada para consumo humano, sendo, a princípio, eliminado com o tratamento da água, apresentando um risco baixo de se contrair a COVID-19 (GU et al., 2020; BHOWMICK et al., 2020). Assim, sobre a deteç̧ão e persistência do SRA-CoV-2 e sua influência na qualidade da água para consumo humano, existe a necessidade da realização de mais pesquisas, corroborando com Gwenzi (2021), que faz uma crítica em relação às evidências atuais e alerta sobre a importância de se fazer inferências precisas sobre os riscos potenciais à saúde humana, uma vez que a detecção do RNA do SARS-CoV-2 em meios ambientais ainda apresenta desafios significativos.

Desse modo, o grande desafio nas áreas rurais ocorre devido ao serviço de saneamento inadequado. Neste estudo, $100 \%$ dos domicílios não recebem água tratada e, por esse motivo, não houve diferença de priorização pela AHP (Tabela 3). Em função dessa realidade, apesar de ter sido atribuído o menor peso para esse critério $(3,5 \%)$ (Tabela 1 ), os prestadores de serviços de abastecimento de água potável e os responsáveis pela vigilância da qualidade da água para consumo humano devem dar uma maior atenção às campanhas imediatas sobre a necessidade da realização de desinfecção no intradomicílio e, o quanto antes, à implantação de sistemas de abastecimento de água adequados.

\section{Hábito de lavar as mãos}

A higienização das mãos está associada a uma menor disseminação de doenças, e os mais variados organismos patogênicos podem ser eliminados ou reduzidos com essa prática (HAQUE et al., 2020). Um estudo realizado por Skolmowska, Glabska e Guzek (2020), na Polônia, avaliou a lavagem das mãos antes e após as refeições e o uso do banheiro, concluindo que esses hábitos estiveram menos presentes em regiões com maior morbidade por COVID-19. Outro estudo que corrobora a temática foi realizado por Gao et al. (2020), na China.

A utilização dos produtos de higiene para as mãos deve ser incentivada, uma vez que estes são eficientes para a inativação do SARS-CoV-2 (MUKHERJEE et al., 2020; LESLIE, ZHOU \& MACINGA, 2020), além de outros patógenos. 


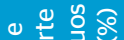




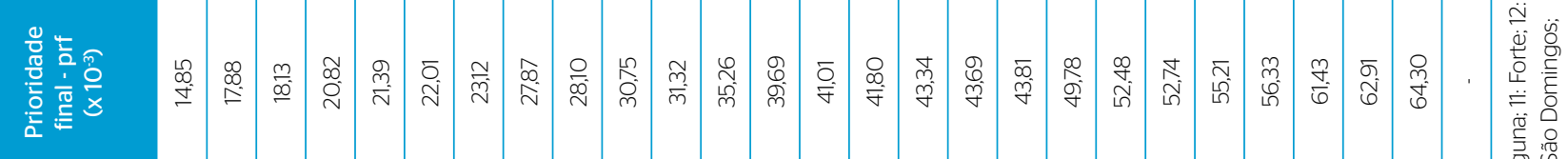

$\approx \frac{0}{0}$

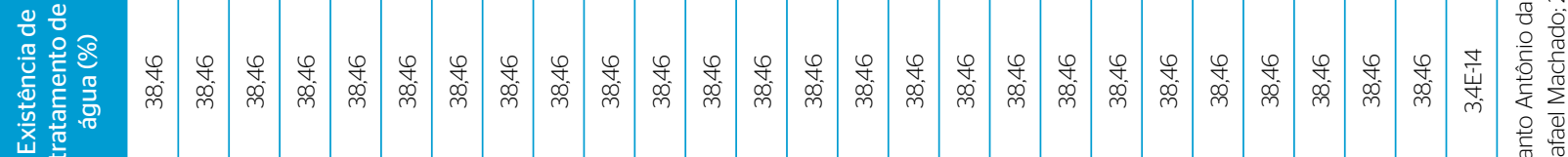

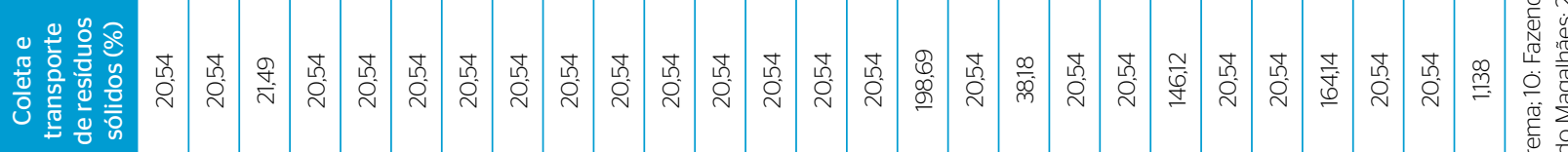

일ㅇㅇ

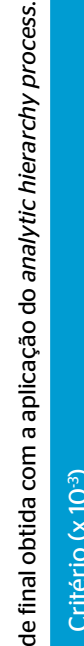

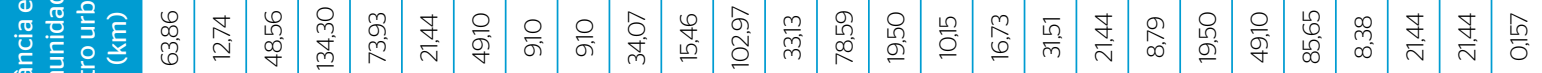

16

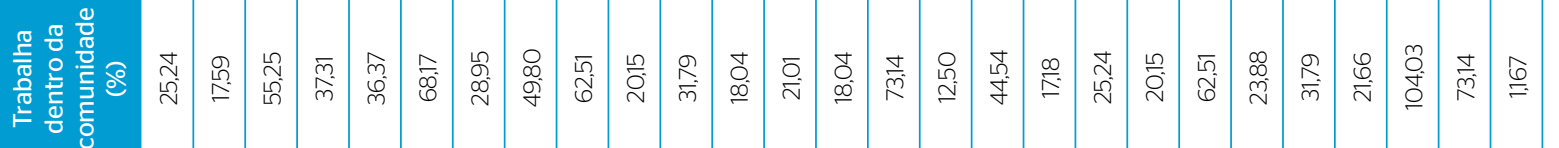

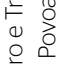

का ข

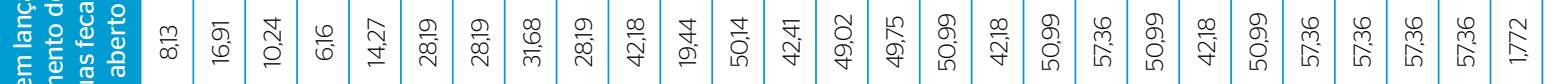

음

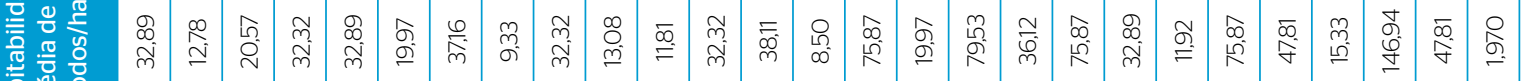

空递

응 운 응

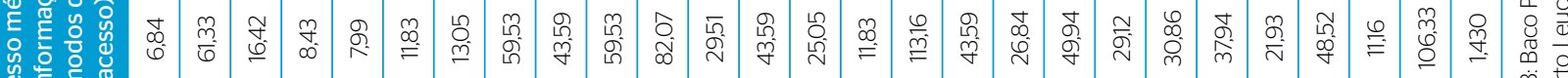

这觉

$\stackrel{\varepsilon}{0} \approx$

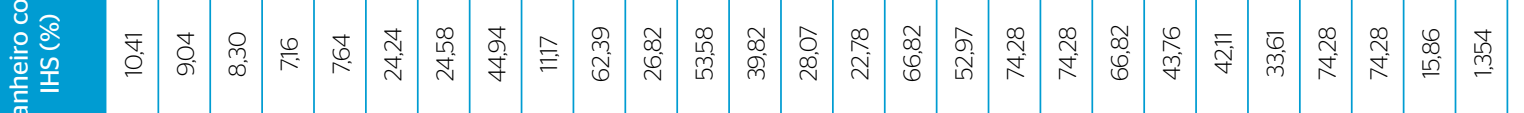
展

突言

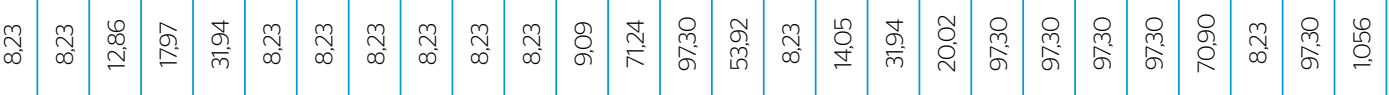

至新

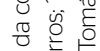

Eे 일

高 @

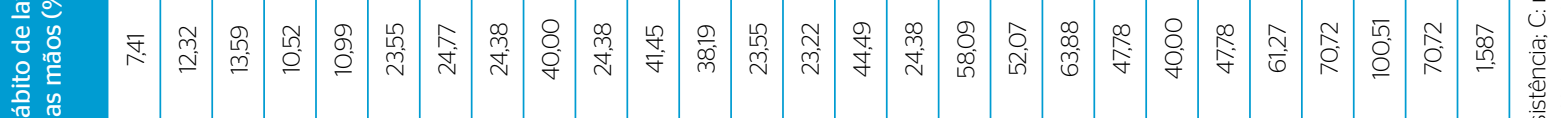

竞兽 


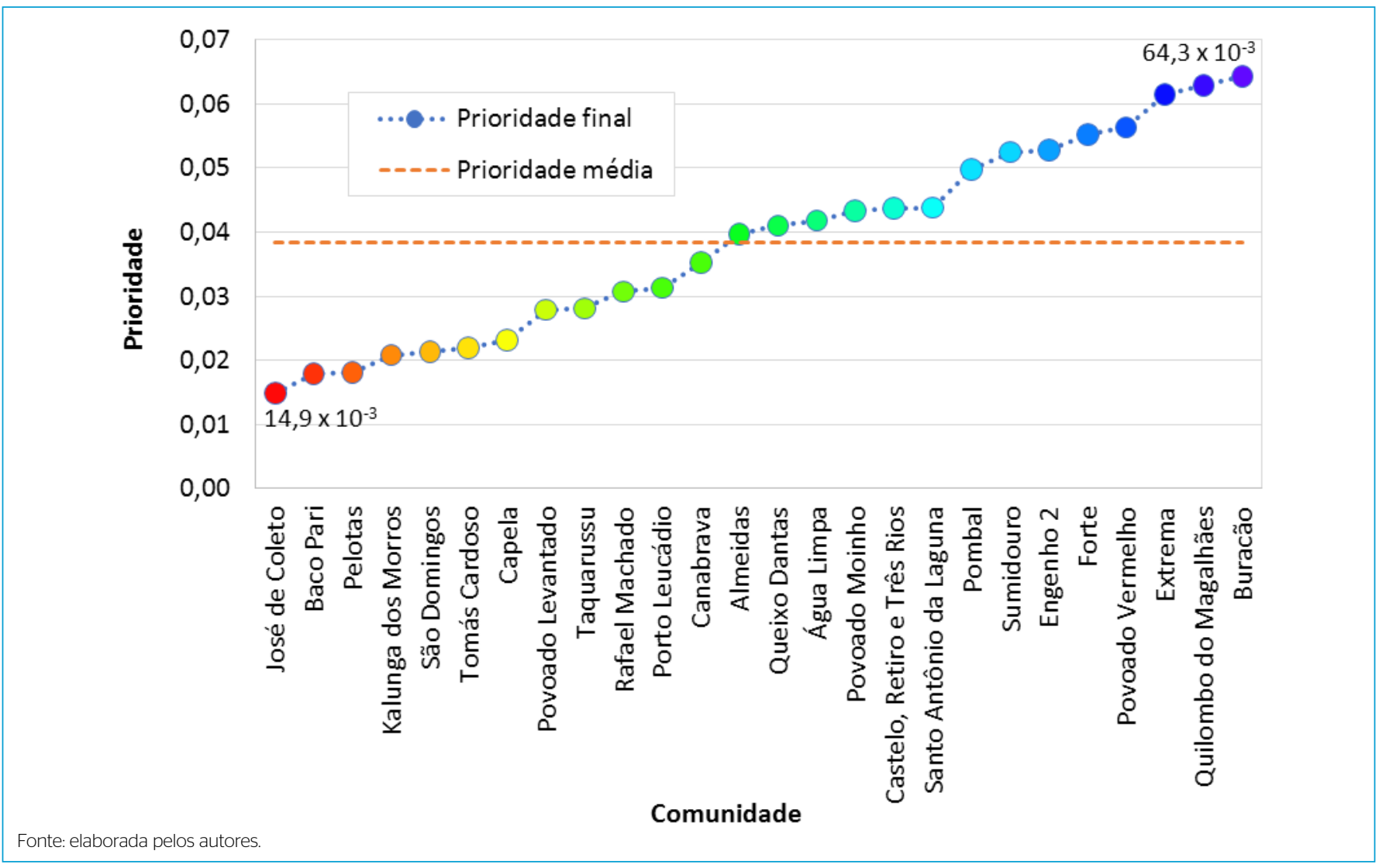

Figura 2 - Prioridade final e média das comunidades em relação à disseminação da COVID-19.

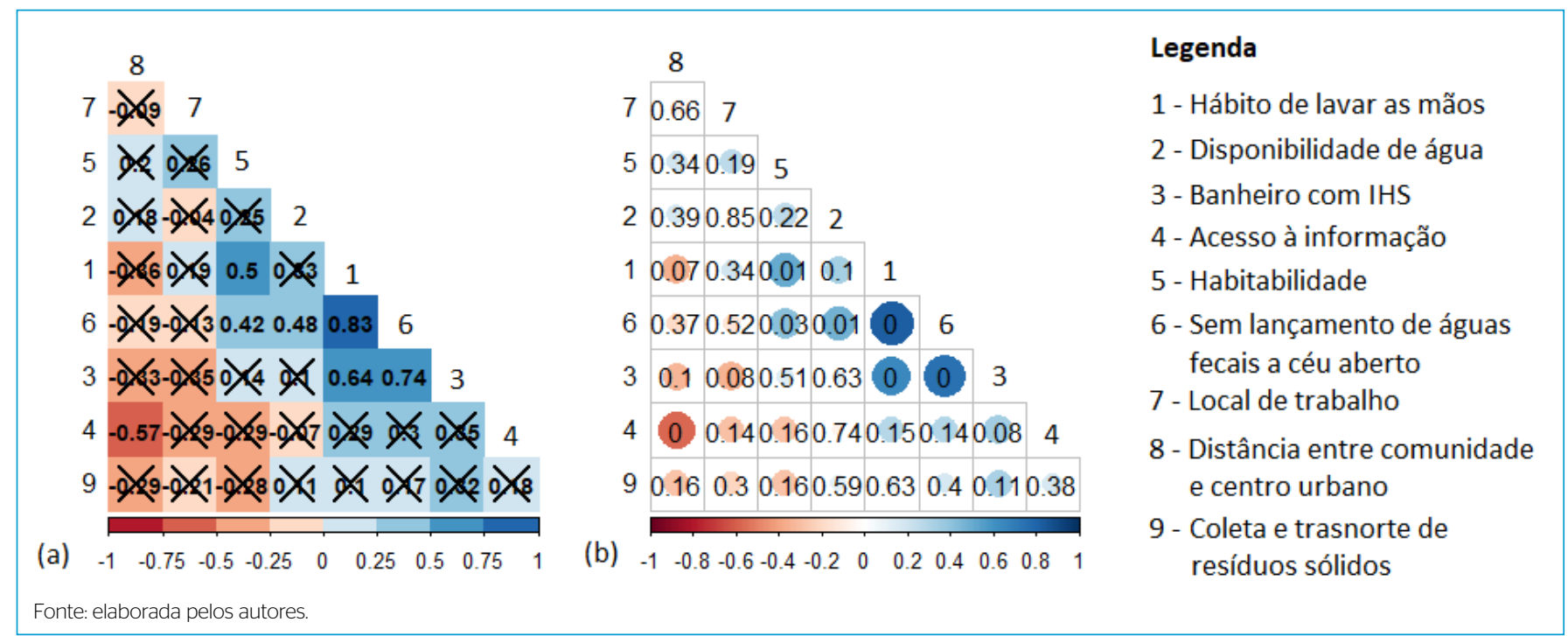

Figura 3 - Correlação de Spearman entre as prioridades de cada critério (A) e os respectivos valores de p dos testes de correlação (B).

Como exemplo, há o estudo de Grayson et al. (2009), no qual se avaliou a eficiência da higienização das mãos com água e sabão e se concluiu que essa ação é altamente eficiente na redução do vírus influenza $\mathrm{A}$, inclusive superior à utilização de álcool.

Nas comunidades estudadas, o hábito de lavar as mãos com água e sabão esteve presente em $51,9 \%$ dos domicílios, impactando os resultados obtidos no
AHP, uma vez que esse critério foi o mais valorizado, apresentando um peso de 27,5\% (Tabela 1). Nesse contexto, deve-se trabalhar esse hábito com os moradores dessas comunidades, principalmente a utilização de sabão, no sentido de difundir sua inclusão nos hábitos diários, uma vez que essa prática contribui significativamente para uma menor disseminação da COVID-19. 
A comunidade mais desfavorável foi a José de Coleto ( $\left.\mathrm{pf}=7,41 \times 10^{-3}\right)$. Em situação oposta, encontra-se a Comunidade Quilombo do Magalhães, com pf $=100,51 \times 10^{-3}$ (Tabela 3 ).

O critério "hábito de lavar as mãos" apresentou uma correlação positiva de 0,64 com "banheiro com IHS" e de 0,83 com domicílios "sem lançamento de águas fecais a céu aberto" (Figura 3). Ou seja, as melhores condições de saneamento podem estimular o hábito de lavar as mãos, o que pode impactar diretamente a redução da disseminação da COVID-19.

\section{Local de trabalho e distância entre comunidade e centro urbano}

O local de trabalho e o método de deslocamento de um indivíduo são importantes para a determinação da possibilidade de contágio, o que está diretamente relacionado ao número de habitantes e de casos ativos da COVID-19. No contexto da disseminação nas comunidades rurais, Ramalho et al. (2020) realizaram um estudo no estado do Amazonas, considerando um deslocamento diário para uma cidade com o distanciamento social implementado. Os autores também observaram que a probabilidade de um indivíduo entrar em contato com uma pessoa com o vírus variou de 25 até $100 \%$.

Ferretti et al. (2020) e Federgruen e Naha (2021) destacam que o transporte coletivo é um dos principais meios de propagação do SARS-CoV-2 na população com menor renda. Contudo, os indivíduos de comunidades rurais se deslocam para a cidade de formas variadas, seja individualmente (a pé, de bicicleta, moto, carro, entre outros) ou por transporte coletivo, o qual é mais presente nas regiões metropolitanas e no Distrito Federal (DF) (RANGEL, DINIZ-FILHO \& TOSCANO, 2020; Codeço et al., 2020; RASCOMBE, 2020). Observando-se a Figura 1 é possível afirmar que a principal rota terrestre de transmissão das comunidades estudadas pode ser o DF, uma vez que $92,3 \%$ das comunidades estão nas suas proximidades, e somente $7,7 \%$ ficam mais próximas de Goiânia. Neste estudo, a distância entre as comunidades e o centro urbano mais próximo variou de 7 a $71 \mathrm{~km}$ (média $=34,1 \mathrm{~km}$ ) (Tabela 2). Conforme apresentado na Tabela 3, a Comunidade de Extrema estaria mais susceptível à disseminação da COVID-19 em função do distanciamento do centro urbano mais próximo $\left(\mathrm{pr}=8,38 \times 10^{-3}\right)$, enquanto a Comunidade Kalunga dos Morros está em condição oposta $\left(\mathrm{pr}=13,43 \times 10^{-3}\right)$, o que pode dificultar a sua disseminação. Além disso, foi detectada uma correlação negativa de -0,57 com o "acesso à informação", ou seja, quanto mais distante a comunidade estiver do centro urbano, menor o acesso à informação (Figura 3).

\section{Esgotamento sanitário}

A presença do vírus SARS-CoV-2 em fezes humanas já foi detectada, sendo que sua capacidade de contaminação no ser humano vem sendo discutida (ZHENG et al., 2020; WU et al., 2020; JEONG et al., 2020). Neste cenário, Zheng et al. (2020) e Wu et al. (2020) mostram a importância de se realizar o manejo e a destinação correta das excretas, a fim de se evitar o contágio com o SARSCoV-2 por transmissão fecal-oral. Desta maneira, a falta de sistemas adequados de esgotamento sanitário em comunidades rurais pode influenciar o contágio, representando uma potencial ameaça (SHADMI et al., 2020; BHOWMICK et al., 2020; WU et al., 2020). No entanto, são necessárias maiores evidências epidemiológicas para confirmar essa hipótese (GWENZI, 2021). Rimoldi et al. (2020) detectaram infectividade nula do SARS-CoV-2 em águas residuárias brutas ou tratadas com a presença de RNA viral e sugerem que a patogenicidade do vírus em águas residuárias e mananciais superficiais, por estarem associadas a riscos para a saúde, deve ser avaliada dentro de uma perspectiva de precaução, dada a natureza preliminar dos resultados.

Contextualizando-se esse cenário, verifica-se que, em média, 14,5\% dos domicílios estudados dispõem a água fecal diretamente no solo (Tabela 2), o que pode possibilitar a disseminação da COVID-19. Esse critério ficou com o sexto maior peso (5,3\%) (Tabela 1). Observou-se ainda uma correlação de 0,83 desse critério com o "hábito de lavar as mãos", 0,74 com "banheiro com IHS", e 0,48 com "disponibilidade de água" (Figura 3).

A destinação das águas cinzas também poderia assumir uma importância na disseminação da COVID-19. No entanto, segundo Hart e Halden (2020), grande parte do decaimento de vírus envelopados pode ocorrer imediatamente após a sua disposição devido à presença de solventes e detergentes ou à adsorção nos sólidos presentes nos esgotos. Assim, isso não foi incluído neste trabalho como critério para a disseminação do SARS-CoV-2.

\section{Banheiro com instalações hidrossanitárias (IHS)}

A presença de banheiro com IHS em um domicílio é fundamental para a manutenção da qualidade de vida. Jones et al. (2020) relataram em seu trabalho de revisão que o risco de disseminação do vírus no uso compartilhado de banheiros domésticos provavelmente será muito baixo, pois geralmente envolve indivíduos com infecções leves. No entanto, Yu et al. (2004) verificaram a propagação do vírus por meio de aerossóis, oriunda das descargas de vasos sanitários e que, por meio de tubulações de esgoto e correntes de ar, contaminaram unidades do condomínio. Assim, os equipamentos hidrossanitários e os utensílios de higiene podem estar expostos à contaminação pelos aerossóis das descargas sanitárias, podendo permanecer por até três horas no ambiente (DOREMALEN et al., 2020). Em função desse cenário, é possível observar que as comunidades quilombolas podem estar suscetíveis ao vírus, visto que vivem em média 3,2 pessoas em um mesmo domicílio, quase sempre com um único banheiro, sendo que 73,0\% dos domicílios possuem banheiro com IHS (Tabela 2) e que 14,5\% dos indivíduos fazem suas necessidades a céu aberto. Esse fato, aliado à falta de medidas governamentais e de segurança, é preocupante, e ações mitigadoras devem ser implementadas (SUN \& HAN, 2020).

Esse critério foi o segundo em maior importância (Tabela 1) e apresentou uma correlação de 0,74 com o critério "sem lançamento de águas fecais a céu aberto" e de 0,64 com "hábito de lavar as mãos" (Figura 3).

\section{Coleta e transporte dos resíduos sólidos}

A gestão e o gerenciamento dos resíduos sólidos são essenciais para reduzir a disseminação de doenças transmissíveis, principalmente a COVID-19 (MOL \& CALDAS, 2020). Logo, se torna imprescindível realizar o manejo adequado dos resíduos (ABES, 2020), visto que eles permanecem por até nove dias, sob temperatura ambiente, em superfícies inanimadas (KAMPF et al., 2020). Assim, os riscos de contaminação tornam-se mais expressivos em áreas onde há precariedade ou ausência da prestação coletiva dos serviços de gerenciamento de resíduos (ARAÚJO \& SILVA, 2020). As comunidades estudadas se enquadram nesse contexto, apresentando $17,8 \%$ dos domicílios com alguma forma de coleta e transporte de resíduos. Na busca por soluções individuais, são adotadas formas inadequadas de disposição, tais como queima, lançamento no quintal e enterramento. Embora a disposição inadequada dos 
resíduos provoque poluição e apresente risco de contágio em caso de contato nas primeiras horas após o descarte (NGHIEM et al., 2020), ainda é pouco comprovado que a rota de disseminação da COVID-19 por resíduos é efetiva aos moradores de área rural.

Esse critério obteve o nono maior peso (Tabela 1), sendo muito favorável às comunidades de Povoado Moinho, Engenho II e Extrema (Tabela 3), pois existem formas coletivas de coleta de resíduos.

\section{Habitabilidade}

Dentre os fatores relevantes para a disseminação de doenças infecciosas está o número de pessoas por unidade de área (HAMIDE, SABOURI \& EWING, 2020; VIBOUD et al., 2004). Os resultados apresentados na Tabela 2 demonstram uma variação média de 1,4 a 4,0 cômodos/hab.domicílio para o critério "habitabilidade" nas comunidades Mimoso e Quilombo do Magalhães, respectivamente, sendo que essa variação pode refletir a identidade cultural dessas comunidades (SELDEN \& BERDAHL, 2020).

O maior valor da correlação de Spearman para a habitabilidade se deu em relação ao parâmetro "higiene de lavar das mãos" (0,5) (Figura 3). Desse modo, quanto mais cômodos, maior será o número de banheiro ou de estruturas diversas que facilitam o hábito de lavar as mãos.

Embora seja de suma importância compreender a possibilidade de disseminação da COVID-19, deve-se considerar que essa variável sofre a influência de outros fatores, tais como a composição da estrutura familiar, as questões de gênero e a composição étnica e etária (ENDO et al., 2019; SELDEN \& BERDAHL, 2020; VIBOUDE et al., 2004), que devem ser abordados sempre que possível. Por outro lado, deve-se ressaltar que, embora o adensamento habitacional das famílias seja um fator preponderante para a disseminação da COVID-19, essa estrutura familiar também pode funcionar como uma rede de apoio em momentos de crise na saúde, elevando-se, assim, a qualidade de vida dessas famílias (HAMIDE, SABOURI \& EWING, 2020).

\section{CONCLUSÕES}

O presente trabalho permite concluir que:

- em função dos critérios selecionados, a aplicação do AHP possibilitou uma priorização final das comunidades quilombolas rurais do estado de Goiás quanto à disseminação da COVID-19, compatível com as condições encontradas;

- as comunidades José de Coleto, Baco Pari, Pelotas, Kalunga dos Morros e São Domingos foram as que se apresentaram mais susceptíveis à disseminação da COVID-19. No lado oposto estão as comunidades do Forte, Povoado Vermelho, Extrema, Quilombo do Magalhães e Buracão, em melhor situação;
- o hábito de lavar as mãos, a disponibilidade de água e a existência de banheiro com IHS, cuja soma dos pesos foi de $60,2 \%$, impactaram a priorização final, conferindo às comunidades em pior situação, nesses critérios, uma maior susceptibilidade à disseminação da COVID-19;

- as melhores condições de saneamento, em termos de presença de banheiros com IHS e a redução do lançamento de águas fecais a céu aberto, podem estimular o hábito de higiene com as mãos, reduzindo a disseminação da COVID-19;

- a partir da correlação de Spearman, observou-se que, quanto melhores as condições de saneamento, maior era o hábito de lavar as mãos, o que pode refletir na redução da disseminação da COVID-19;

- os resultados obtidos apontam para um déficit nos critérios avaliados, necessitando-se de uma maior atenção dos órgãos gestores quanto à minimização da disseminação da COVID-19 e de outras doenças infecciosas.

Portanto, com base na reflexão apresentada neste estudo, faz-se necessário orientar as comunidades sobre a importância dos hábitos de lavar as mãos e das condições de saneamento, uma vez que pequenas mudanças de comportamento minimizam consideravelmente a possibilidade da disseminação da COVID-19 e de outras doenças nas comunidades quilombolas rurais de Goiás.

\section{AGRADECIMENTOS}

Os autores agradecem à Fundação Nacional da Saúde (FUNASA) pelo suporte financeiro, através do projeto intitulado Saneamento e Saúde Ambiental em Comunidades Rurais e Tradicionais de Goiás (SanRural) - TED 05.

\section{CONTRIBUIÇÃO DOS AUTORES}

Scalize, P. S.: conceituação, curadoria de dados, análise formal, metodologia, escrita - primeira redação, obtenção de financiamento, revisão. Bezerra, N. R.: conceituação, metodologia, escrita - revisão. Oliveira, T. L.: escrita - primeira redação, discussão dos resultados, revisão. Baumann, L. R. F.: metodologia, análises estatísticas, escrita - primeira redação. Ruggeri Junior, H. C.: escrita - primeira redação, discussão dos resultados, revisão. Basso, R. E.: escrita primeira redação, discussão dos resultados, revisão. Espírito Santo Filho, K.: escrita - primeira redação, discussão dos resultados, revisão. Chagas, I. M.: escrita, discussão dos resultados, revisão. Aguiar, T.: escrita - primeira redação, discussão dos resultados, revisão. Vale, G. B.: escrita - primeira redação, discussão dos resultados, revisão. Braga, D. L.: escrita - primeira redação, discussão dos resultados, revisão. Pinheiro, R. V. N.: escrita - primeira redação, discussão dos resultados, revisão.

\section{REFERÊNCIAS}

de Resultados, 2020. Disponível em: http://abes-dn.org.br/wp-content/ uploads/2020/08/Pesquisa-ABES-2.1-Pandemia-COVID-19-RSUCapitais-26.8.2020-2.pdf. Acesso em: 15 set. 2021. 
ARAÚJO, E. C. S.; SILVA, V. F. A. Gestão de Resíduos Sólidos em Época de Pandemia do COVID-19. GeoGraphos, v. 11, n. 129, p. 192-215, 2020. https://doi. org/10.14198/GEOGRA2O20.11.129

BHOWMICK, G. D.; DHAR, D.; NATH, D.; GHANGREKAR, M. M.; BANERJEE, R.; DAS, S.; CHATTERJEE, J. Coronavirus disease 2019 (COVID-19) outbreak: some serious consequences with urban and rural water cycle. Clean Water, v. 3, n. 32, 2020. https://doi.org/10.1038/s41545-02O0079-1

CABRAL, A. D.; CLARO, I. C. M.; AUGUSTO, M. R.; FRIOLANI, V. N.; BEZERRA, C. E.; GRACIOSA, M. C. P.; FONSECA, F. L. A.; SPERANÇA, M. A.; BUENO, R. F. Padronização de método de concentração e extração de ácidos nucleicos em amostras de esgoto sanitário: uma ferramenta de baixo custo para ser utilizada na vigilância epidemiológica de SARS-CoV-2. Engenharia Sanitária e Ambiental, edição especial, 2020.

Carducci, A.; FEDERIGI, I.; LIU, D.; THOMPSON, J. R.; VERANI, M. Making Waves: Coronavirus detection, presence and persistence in the water environment: State of the art and knowledge needs for public health. Water Research, v. 179, p. 115907, 2020. https://doi.org/10.1016/j. watres.2020.115907

CARRATURO, F.; GIUDICE, C. D.; MORELLI, M.; CERULLO, V.; LIBRALATO, G.; GALDIERO, E.; GUIDA, M. Persistence of SARS-CoV-2 in the environment and COVID-19 transmission risk from environmental matrices and surfaces. Environmental Pollution, v. 265, part B, p. 115010, 2020. https://doi. org/10.1016/j.envpol.2020.115010

COCHRAN, W. G. Sampling Techniques. New York: John Wileyand Sons, 1977. 448p.

CODEÇO, C.T.; VILLELA, D.; COELHO, F.; BASTOS, L. S.; GOMES, M. F. C.; CRUZ, O. G.; LANA, R. M.; PIOTTI, A. P.; VESPIGNANI, A.; DAVIS, J. T. Estimativa de risco de espalhamento da COVID-19 no Brasil e avaliação da vulnerabilidade socioeconômica nas microrregiões brasileiras. 20 Relatório, Núcleo de Métodos Analíticos para Vigilância em Saúde Pública do PROCC. Rio de Janeiro: Fiocruz e EMAp/FGV, 2020. Disponível em: https://www.arca.fiocruz.br/handle/icict/40509. Acesso em: 15 out. 2021.

DEHGHANI, R.; KASSIRI H. A Brief Review on the possible role of house flies and cockroaches in the mechanical transmission of coronavirus disease 2019 (COVID-19). Archives of Clinical Infectious Diseases, v. 15, e102863, 2020. https://doi.org/10.5812/archcid.102863

DUTTA, A.; FISCHER, H. W. The local governance of COVID-19: Disease prevention and social security in rural India. World Development, v. 138, p. 105234, 2021. https://doi.org/10.1016/j.worlddev.2020.105234

ENDO, A.; UCHIDA, M.; KUCHARSKI, A. J.; FUNK, S. Fine-scale family structure shapes influenza transmission risk in households: Insights from primary schools in Matsumoto city, 2014/15. PLoS Computational Biology, v. 15, n. 12 , p. 1-18, 2019. https://doi.org/10.1371/journal.pcbi.1007589

EKUMAH, B.; ARMAH, F. A.; YAWSON, D. O.; QUANSAH, R.; NYIEKU, F. E.; OWUSU, S. A.; ODOI, J. O.; AFITIRI, A. R. Disparate on-site access to water, sanitation, and food storage heighten the risk of COVID-19 spread in SubSaharan Africa. Environmental research, v. 189, p. 109936, 2020. https://doi. org/10.1016/j.envres.2020.109936

FEDERGUEN, A.; NAHA, S. Crowding Effects Dominate Demographic Attributes in COVID-19 Cases. International Journal of Infectious Diseases, v. 102, p. 509-516, 2021. https://doi.org/10.1016/j.jiji.2020.10.063
FERRARETTO, L. A.; MORGADO, F. COVID-19 e comunicação um guia prático para enfrentar a crise. Rio de Janeiro: Válega, 2020. 63 p. Disponível em: http://hdl.handle.net/10183/213925. Acesso em: 15 out. 2021.

FERRETTI, L.; WYMANT, C.; KENDALL, M.; ZHAO, L.; NURTAY, A.; ABELERDÖRNER, L.; BONSALL, M. P. D.; FRASER, C. Quantifying SARS-CoV-2 transmission suggests epidemic control with digital contact tracing. Science, v. 368, n. 6491, 2020. https://doi.org/10.1126/science.abb6936

GAO, C.; ZHAO, Z.; LI, F.; LIU, J. L.; XU, H.; ZENG, Y.; YANG, L.; CHEN, J.; WANG, C.; GUO, Q. The impact of individual life style and status on the acquisition of COVID-19: A case - Control study. PLoS ONE, v. 15, n. 11, 2020. https://doi. org/10.1371/journal.pone.0241540

GOEPEL, K. D. Implementing the analytic hierarchy process as a standard method for multi-criteria decision making in corporate enterprises - A new AHP Excel template with multiple inputs. Proceedings of the International Symposium on the Analytic Hierarchy Process. Anais..., Kuala Lumpur, Malaysia, p. 23-26, 2013.

GRAYSON, M. L.; MELVANI, S.; DRUCE, J.; BARR, I. G.; BALLARD, S. A.; JOHNSON, P. D. R.; MASTORAKOS, T.; BIRCH, C. Efficacy of soap and water and alcohol-based hand-rub preparations against live H1N1 influenza virus on the hands of humanvolunteers. Clinical Infectious Diseases, v. 48, n. 3 , 2009, p. 285-291. https://doi.org/10.1086/595845

GU, J.; HAN, B.; WANG, J. COVID-19: gastrointestinal manifestations and potential fecal-oral transmission. Gastroenterology, v. 158, n. 6, p. 1518-519, 2020. https://doi.org/10.1053/j.gastro.2020.02.054

GUERRERO-LATORRE, L.; BALLESTEROS, I.; VILLACRÉS-GRANDA, I.; GRANDA, M. G.; FREIRE-PASPUEL, B.; RIOS-TOUMA, B. SARS-COV-2 in riverwater: Implications in low sanitation countries. Science of the Total Environment, v. 743, p. 140832, 2020. https://doi.org/10.1016/j. scitotenv.2020.140832

GWENZI, W. Leaving no stone unturned in light of the COVID-19 fecal-oral hypothesis? A water, sanitation and hygiene (WASH) perspective target in glow-income countries. Science of the Total Environment, v. 753, p. 141751 2021. https://doi.org/10.1016/..scitotenv.2020.141751

HAQUE, M.; MCKIMM, J.; SARTELLI, M.; DHINGA, S.; LABRICCIOSA, F. M.; ISLAM, S.; JAHAN, D.; NUSRAT, T.; CHOWDHURY, T. S.; COCCOLINI, F.; ISKANDAR, K.; CATENA, F.; CHARAN, J. Strategies to Prevent Health care -Associated Infections: A Narrative Overview. Risk Manag Healthc Policy, v. 13, p. 1765-1780, 2020. https://doi.org/10.2147/RMHP.S269315

HART, O. E.; HALDEN, R. U. Computation alanalysis of SARS-CoV-2/ COVID-19 surveillance by waste water-based epidemiology local land globally: Feasibility, economy, opportunities and challenges. Science of the Total Environment, v. 730, 2020. https://doi.org/10.1016/j. scitotenv.2020.138875

HAMIDI, S.; SABOURI, S.; EWING, R. Does Density Aggravate the COVID-19 Pandemic? Journal of the American Planning Association, v. 86, n. 4, p. 495509, 2020. https://doi.org/10.1080/01944363.2020.1777891

HANSEN, J. C.; CARPENTIER, J. P. Preparing staff for the swine flu pandemic: Information and communication channels. Journal of Communication in Healthcare, v. 8068, 2013. https://doi.org/10.1179/cih.2009.2.4.316

HAUER, M. K.; SOOD, S. Using Social Media to Communicate Sustainable Preventive Measures and Curtail Misinformation. Frontiers Psychology, v. 11, n. 568324, p. 1-6, 2020. https://doi.org/10.3389/fpsyg.2020.568324 
HENNING-SMITH, C. The Unique Impact of COVID-19 on Older Adults in Rural Areas. Journal of Aging \& Social Policy, v. 32, n. 4-5, p. 396-402, 2020. https://doi.org/10.1080/08959420.2020.1770036

JEONG, H. W.; KIM, S. M.; KIM, H. S.; KIM, Y. I.; KIM, J. H.; CHO, J. Y.; KIM, S. H.; KANG, H.; KIM, S. G.; PARK, S. J.; KIM, E. H.; CHOI, Y. K. Viable SARSCoV-2 in various specimens from COVID-19 patients. Clinical Microbiology and Infection, v. 26, n. 11, p. 1520-1524, 2020. https://doi.org/10.1016/j. cmi.2020.07.020

JONES, D. L.; BALUJA, M. Q.; GRAHAM, D. W.; CORBISHLEY, A.; MCDONALD, J. E.; MALHAM, S. K.; HILLARY, L. S.; CONNOR, T. R.; GAZE, W. H.; MOURA, I. B.; WILCOX, M. H.; FARKAS, K. Shedding of SARS-COV-2 in feces and urine and its potential role in person-to-person transmission and the environmentbased spread of COVID-19. Science of the Total Environment, v. 749, p. 141364, 2020. https://doi.org/10.1016/j.scitotenv.2020.141364

KAMPF, G.; TODT, D.; PFAENDER, S., STEINMANN, E. Persistence of coronavirus on inanimate surfaces and their inactivation with biocidal agents. Journal of Hospital Infection, v. 104, n. 3, p. 246-251, 2020. https://doi. org/10.1016/j.jhin.2O20.01.022

KENDALL, M. G.; GIBBSONS, J. D. Rank correlation methods. London: Edward Arnold, 1990.

KUMAR, P.; CHANDER, B. COVID 19 mortality: Probable role of microbiome to explain disparity. Medical Hypotheses, v. 144, p. 110209, 2020. https://doi. org/10.1016/j.mehy.2020.110209

LESLIE, R. A.; ZHOU, S. S.; MACINGA, D. R. Inactivation of SARS-CoV-2 by commercially available alcohol-based hand sanitizers. American Journal of Infection Control, 2020. https://doi.org/10.1016/j.ajic.2020.08.020

LUO, R. F.; LIU, C. F.; GAO, J. J.; WANG, T. Y.; ZHI, H. Y.; SHI, P. F.; HUANG, J. K. Impacts of the COVID-19 pandemic on rural poverty and policy responses in China. Journal of Integrative Agriculture, v. 19, n. 12, p. 2646-2964, 2020. https://doi.org/10.1016/S2095-3119(20)63426-8

MALECKI, K. M. C.; KEATING, J. A.; SAFDAR, N. Crisis Communication and Public Perception of COVID-19 Risk in the Era of Social Media. Clinical Infectious Diseases, p. 1-6, 2020. https://doi.org/10.1093/cid/ciaa758

MOL, M. P. G.; CALDAS, S. Can the human corona virus epidemical so spread through solid waste? Waste Management \& Research, v. 38, n. 5, p. 485-486, 2020. https://doi.org/10.1177/0734242X20918312

MOHAMAD, E;; AZLAN, A. A. COVID-19 and Communication Planning for Health Emergencies. University Kebangsaan Malaysia CORRESPONDENCE, 2020.

MUKHERJEE, S.; VINCENT, C. K.; JAYASEKERA, H. W.; YEKHE, A. S. Antiviral efficacy of personal care formulations against Severe Acute Respiratory Syndrome Coronavirus 2. Infection, Disease \& Health, 2020. https://doi. org/10.1016/j.idh.2020.09.003

NEDEL, F. B. Enfrentando a COVID-19: APS forte agora mais que nunca! APS em Revista. v. 2, n. 1, p. 11-16. 2020. https://doi.org/10.14295/aps.v2i1.68

NGHIEM, L. D.; MORGAN, B.; DONNER, E.; SHORT, M. D. The COVID-19 pandemic:

considerations for the waste and waste water services sector. Chemical and Environmental Engineering, v. 1, p. 1000006, 2020. https://doi.org/10.1016/j. cscee.2020.100006

RAMALHO, E. E.; JUNQUEIRA, I.; BACCARO, F.; HILL, A. L.; MARTINS, M. I. F. P. O.; BARCELOS, D. C.; FERREIRA-FERREIRA, J.; PEREIRA, H. C.; CORREA, D.
S. S.; CHAGAS, H. C.; NASCIMENTO, A. C. S. Disseminação da COVID-19 em cidades e localidades rurais da Amazônia Central. n. 3, p. 1-18, 2020. https:// doi.org/10.1590/SciELOPreprints.406

RANGEL, T. F.; DINIZ-FILHO, J. A. F.; TOSCANO, C. Modelagem da expansão espaço- temporal da COVID-19 em Goiás. Goiânia: IPTSP, 2020.

RASCOMBE, P. Rural areas at risk during COVID-19 pandemics. The Lancet Infection Diseases, v. 20, n. 5, p. 545, 2020. https://doi.org/10.1016/S14733099(20)30301-7

RIMAL, R. N.; LAPINSKI, M. K. Why health communication is important in public health. Bull World Health Organ, v. 87, n. 547, p. 247-248, 2009. https:/l doi.org/10.2471/BLT.08.056713

RIMOLDI, S. G.; STEFANI, F.; GIGANTIELLO, A.; POLESELLO, S. COMANDATONE, F; MILETO, D.; MARESCA, M.; LONGOBARDI, C.; MANCON A.; ROMERI, F.; PAGANI, C.; CAPPELI, F.; ROSCIOLI, C.; MOJA, L.; GISMONDO, M. R.; SALERMO, F. Presence and infectivity of SARS-CoV-2 virus in waste waters and rivers. Science of the Total Environment, v. 744, p. 140911, 2020 https://doi.org/10.1016/j.scitotenv.2020.140911

SAATY, R. W. The analytic hierarchy process - what it is and how it is used. Mathematical modelling, v. 9, n. 3-5, p. 161-176, 1987. https://doi org/10.1016/0270-0255(87)90473-8

SAATY, T. L.; TRAN, L. T. On the invalidity of fuzzifying numerical judgments in the Analytic Hierarchy Process. Mathematical and Computer Modelling. v. 46, n. 7-8, p. 962-975, 2007. https://doi.org/10.1016/j.mcm.2007.03.022

SAUD, M.; MASHUD, M.; IDA, R. Usage of social media during the pandemic : Seeking support and awareness about COVID-19 through social media platforms. Journal Public Affairs, v. 20, n. e2417, p. 1-9, 2020.

SELDEN, T. M.; BERDAHL, T. A. COVID-19 And Racial/Ethnic Disparities In Health Risk, Employment, And Household Composition. Health Affairs, v. 39, n. 9, p. 1624-1632, 2020. https://doi.org/10.1377/hlthaff.2020.00897

SHADMI, E.; CHE, Y.; DOURADO, I.; PARAN-PERACH, I.; FURLER, J.; HANGOMA, P.; HANVORAVONGCHAI, P.; OBANDO C.; PETROSYAN, V.; RAO, K. D.; PUANO, A. L.; SHI, L.; SOUZA, L. E.; SPITZER-SHOHAT, S.; STRUGISS, E.; SUPHANCHAIMAT, R.; URIBE, M. V.; WILLEMS, S. Health equity and COVID-19: global perspectives. International Journal for Equity in Health, v. 19, n. 104, 16p, 2020. https://doi.org/10.1186/s12939-020-01218-z

SHUTLER, J.; ZARASKA, K.; HOLDING T.; MACHNIK, M.; UPPULURI, K.; ASHTON, I.; MIGDAL, L.; DAHIYA, R. Risk of SARS-COV-2 infection from contaminated water systems. MedRXIV, 2020. https://doi. org/10.1101/2020.06.17.20133504

SILVA, N. M.; BASTOS, R. M.; CONCEIÇÃO, V. R. C.; BASTOS, A. S. C.; SALES, G. S.; SILVA, T. N. Health promotion in Brazil in pandemic by COVID-19: conceptions and practices in basic care. Saúde Coletiva, v. 10, n. 58, p. 4026-4030. 2020. https://doi.org/10.36489/saudecoletiva.2O2Ov10i5 $8 \mathrm{p} 4021-4030$

SKOLMOWSKA, D.; GLABSKA, D.; GUZEK, D. Hand hygiene behaviors in a representative sample of polish adolescents in regions stratified by COVID-19 morbidity and by confoundingvariables (place-19 study): is there any association? Phathogens, v. 9, n. 12, 2020. https://doi.org/10.3390/ pathogens9121011

SUN, S.; HAN, J. Open defecation and squat toilets, an overlooked risk of fecal transmission of COVID-19 and other pathogens in developing communities. Environmental chemistry letters, p. 1-9, 2020. https://doi. org/10.1007/s10311-020-01143-1 
SUNDARAM, N.; SCHAETTI, C.; PUROHIT, V.; KUDALE, A.; WEISS, M. G. Cultural epidemiology of pandemic influenza in urban and rural Pune, India: a cross sectional, mixed-methods study. BMJ Open, v. 4, 12p, 2015. https://doi.org/10.1136/bmjopen-2014-006350

VIBOUD, C.; BOËLLE, P. W.; CAUCHEMEZ, S.; LAVENU, A.; VALLERON, A. J.; FLAHAULT, A.; CARRAT, F. Risk factors of influenza transmission in households. British Journal of General Practice, v. 54, n. 506, p. 684-689, 2004.

WU, Y.; GUO, C.; TANG, L.; HONG, Z.; ZHOU, J.; DONG, X.; YIN, H.; XIAO, Q.; TANG, Y.; QU, X.; KUANG, L.; FANG, X.; MISHRA, N.; LU, J.; SHAN, H.; JIANG, G.; HUANG, $X$. Prolonged presence of SARS-CoV-2 viral RNA in faecal samples. Lancet Gastroenterol Hepatol, v. 5, p. 434-435. 2020. https://doi.org/10.1016/ S2468-1253(20)30083-2

YU, I. T. S.; LI, Y.; WONG, T. W.; TAM, W.; CHAN, A. T.; LEE, J. H. W.; LEUNG, D. Y. C.; HO, T.. Evidence of Airborne Transmission of the Severe Acute
Respiratory Syndrome Virus. The New England Journal of Medicine, v. 350, n. 17, p. 1731-1739, 2004. https://doi.org/10.1056/NEJMoa032867

ZHENG, S.; FAN, J; YU, F; FENG, B.; LOU, B; ZOU, Q; XIE, G.; LIN, S.; WANG, R.; YANG X:; CHEN, W: WANG, Q; ZHANG, D.; LIU, Y., GONG, R:; MA, Z; LU, Z:; XIAO, Y:; GU, Y: ZHANG, J: YAO, H.; XU, K.: LU, X.; WEI, G.; ZHOU, G.; FANG, Q; CAI, H.; QIU, Y.; SHENG, J.: CHEN, Y.: LIANG, T. Viral load dynamics and disease severity in patients infected with SARS CoV-2 in Zhejiang province, China, January-March 2O2O: retrospective cohort study. The BMJ, v. 369, 2020. https://doi.org/10.1136/bmj.m1443

ZHU, Y:; XIE, J.; HUANG, F; CAO, L. Association between short-term exposure to air pollution and COVID-19 infection: evidence from China. Science of the Total Environment,v. 727,p.138704,2020.https://doi.org/10.1016/j.scitotenv.2020.138704

ZVOBGO, L.; DO, P. COVID-19 and the call for 'Safe Hands': Challenges facing the under-resourced municipalities that lack potable water access-A case study of Chitung wiza municipality, Zimbabwe. Water Research X, v. 9, p. 100074, 2020. https://doi.org/10.1016/j.wroa.2020.100074 
Anexo 1 - Distribuição espacial dos domicílios existentes nas comunidades quilombolas rurais do estado de Goiás utilizadas neste estudo

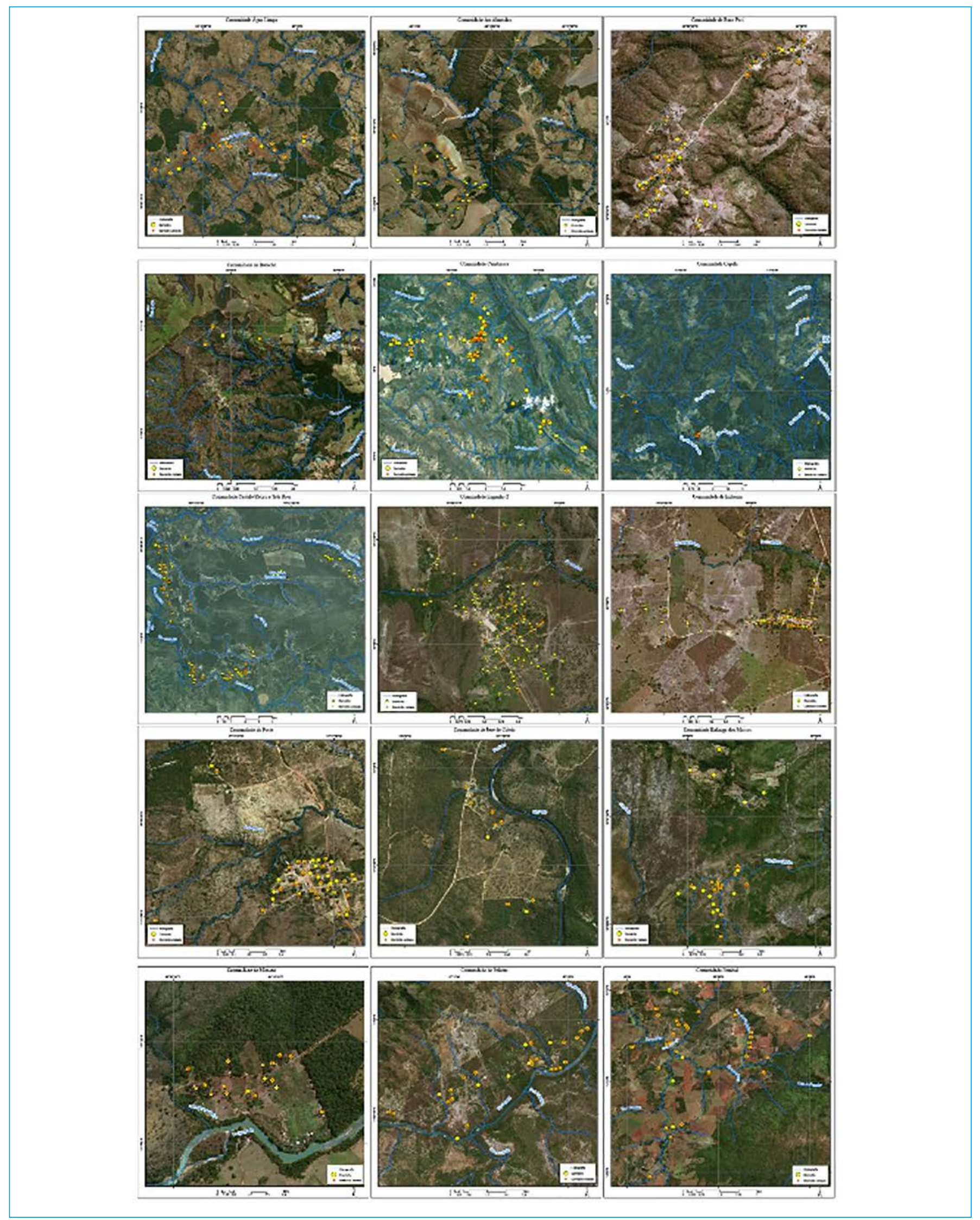


Anexo 1 - Continuação.
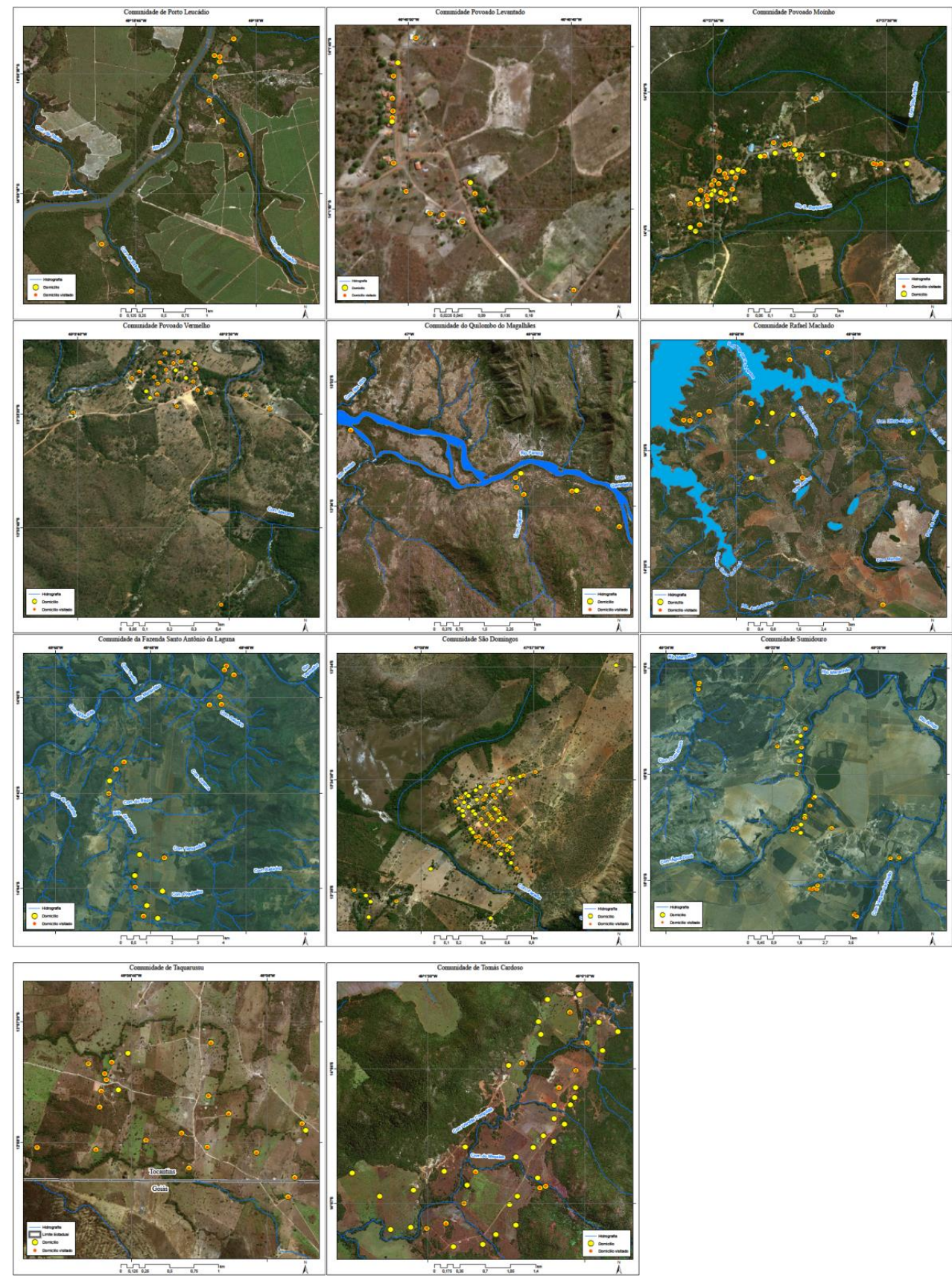

Fonte: elaborada pelos autores. 